\title{
Effects of mesenchymal stromal cells versus serum on tendon healing in a controlled experimental trial in an equine model
}

\author{
A. B. Ahrberg ${ }^{1,2^{*}+}$, C. Horstmeier ${ }^{2,3,4+}$, D. Berner ${ }^{5}$, W. Brehm ${ }^{2,3,4}$, C. Gittel ${ }^{4}$, A. Hillmann ${ }^{2,3}$, C. Josten $^{1}$, G. Rossi ${ }^{6}$, \\ S. Schubert ${ }^{2,3,7}$, K. Winter $^{4,8}$ and J. Burk B $^{2,3,7,9}$
}

\begin{abstract}
Background: Mesenchymal stromal cells (MSC) have shown promising results in the treatment of tendinopathy in equine medicine, making this therapeutic approach seem favorable for translation to human medicine. Having demonstrated that MSC engraft within the tendon lesions after local injection in an equine model, we hypothesized that they would improve tendon healing superior to serum injection alone.

Methods: Quadrilateral tendon lesions were induced in six horses by mechanical tissue disruption combined with collagenase application 3 weeks before treatment. Adipose-derived MSC suspended in serum or serum alone were then injected intralesionally. Clinical examinations, ultrasound and magnetic resonance imaging were performed over 24 weeks. Tendon biopsies for histological assessment were taken from the hindlimbs 3 weeks after treatment. Horses were sacrificed after 24 weeks and forelimb tendons were subjected to macroscopic and histological examination as well as analysis of musculoskeletal marker expression.

Results: Tendons injected with MSC showed a transient increase in inflammation and lesion size, as indicated by clinical and imaging parameters between week 3 and $6(p<0.05)$. Thereafter, symptoms decreased in both groups and, except that in MSC-treated tendons, mean lesion signal intensity as seen in T2w magnetic resonance imaging and cellularity as seen in the histology $(p<0.05)$ were lower, no major differences could be found at week 24 .

Conclusions: These data suggest that MSC have influenced the inflammatory reaction in a way not described in tendinopathy studies before. However, at the endpoint of the current study, 24 weeks after treatment, no distinct improvement was observed in MSC-treated tendons compared to the serum-injected controls. Future studies are necessary to elucidate whether and under which conditions MSC are beneficial for tendon healing before translation into human medicine.
\end{abstract}

Keywords: MSC, Serum, Animal model, Tendon, Horse

\section{Background}

In orthopedic surgery and sports medicine, tendinopathy has become one of the most challenging conditions. Achilles tendinopathy, for example, is a growing problem with a high incidence [1]. Various therapies have been tried without lasting success [2-8]. This underlines the need for a

\footnotetext{
* Correspondence: annette.ahrberg@medizin.uni-leipzig.de

${ }^{\dagger}$ A. B. Ahrberg and C. Horstmeier contributed equally to this work.

${ }^{1}$ Department of Orthopedics, Traumatology and Plastic Surgery, University of Leipzig, Liebigstr. 20, 04103 Leipzig, Germany

${ }^{2}$ Translational Center for Regenerative Medicine (TRM), University of Leipzig,

Leipzig, Germany

Full list of author information is available at the end of the article
}

new curative therapy from the field of regenerative medicine. The horse, which could be referred to as animal athlete, suffers from a natural tendinopathy in its superficial digital flexor tendon (SDFT) which is similar to the Achilles tendon in its structure, function and pathophysiology [9-12]. Therefore, horses are considered as highly suitable model animals for orthopedic research and have been recommended by authorities such as the U.S. Food and Drug Administration (FDA) and the European Medicines Agency (EMA) [13, 14]. Contrary to human medicine, regenerative cell therapies have already been used in equine medicine for more than a decade, with most

(c) The Author(s). 2018 Open Access This article is distributed under the terms of the Creative Commons Attribution 4.0 International License (http://creativecommons.org/licenses/by/4.0/), which permits unrestricted use, distribution, and reproduction in any medium, provided you give appropriate credit to the original author(s) and the source, provide a link to the Creative Commons license, and indicate if changes were made. The Creative Commons Public Domain Dedication waiver (http://creativecommons.org/publicdomain/zero/1.0/) applies to the data made available in this article, unless otherwise stated. 
experiences in multipotent mesenchymal stromal cells (MSC) therapy for tendon disease [15]. Clinical results are promising, although the mechanisms of action leading to improved tendon healing are not yet fully understood [11, 16, 17].

MSC are adult progenitor cells displaying plastic-adherence and multipotent differentiation potential in vitro and can be further characterized by a set of surface marker antigens [18]. They can be extracted from various tissues, e.G. adipose tissue or bone marrow and are thought to support tissue regeneration not only by cell replacement, but also via trophic and modulatory effects which are mediated by cell-cell contact or paracrine mechanisms [19-21].

The promising results of MSC therapy in equine patients make a translation into human medicine appear reasonable. Recently we were able to show that adipose-derived MSC engrafted within tendon lesions after local injection in an equine model although there was also systemic distribution of a small number of cells [22]. These results were obtained on the basis of labeling the MSC with superparamagnetic iron oxide (SPIO) and rhodamine. After demonstrating long-term MSC persistence we aimed to evaluate the effect of these MSC on tendon healing within the same set of animals as presented in the current study. We hypothesized that local injection of adipose-derived MSC improves outcome parameters obtained by clinical imaging and histological assessment as well as gene expression analysis over a follow-up period of 24 weeks.

\section{Methods}

\section{Study design}

Tendinopathy of the SDFT was induced in all limbs of 6 horses and autologous adipose tissue was harvested (week -3). MSC were expanded and labeled with SPIO. MSC resuspended in serum or serum alone were injected into the left and right tendon lesions 3 weeks after their induction (week 0). Clinical examinations and diagnostic imaging were performed over 24 weeks (week $0,1,2,3,4,6,8,12$ and 24). Tendon biopsies were taken after 3 weeks from the hindlimb SDFT for early histological evaluation (week 3). After euthanasia at week 24, forelimb SDFT were harvested for macroscopic and late histological evaluation and for analysis of musculoskeletal marker expression. Approval of the local ethics committee (TVV 34/13) had been given beforehand.

\section{Animals}

Six horses (standardbred; mean age: 6 years; age range: 3-10 years; 3 female, 3 male; body weight: $400-550 \mathrm{~kg}$ ) were included in the study. The horses were obtained from trot racing courts in accordance with the local authority. Clinical evaluation, ultrasound (US) and Magnetic Resonance Imaging (MRI) of all extremities were performed prior to the first surgery to ensure the animals were healthy. The horses were housed in the hospital's stables. All procedures were performed within the facility, so no transport of the horses was needed.

\section{Induction of tendinopathy and adipose tissue collection}

Tendinopathy was induced by minor mechanical tissue disruption combined with a low-dose injection of collagenase type I $(4.8 \mathrm{mg} / \mathrm{mL}$, Life Technologies $\mathrm{GmbH}$, Darmstadt, Germany) in the SDFT of all 4 extremities under general anesthesia (week -3). With the horse placed in lateral position, the skin was clipped and prepared aseptically. An 11-gauge bone marrow aspiration needle was introduced into the SDFT in the middle of the metatarsal/metacarpal region via a skin incision. $0.4 \mathrm{~mL}$ collagenase type I (250 IU per tendon lesion) were injected while removing the needle from $2 \mathrm{~cm}$ proximal to $1 \mathrm{~cm}$ proximal from its entry point without further damage of the epitenon. The incisions in the peritendineum and skin were closed by suture and a dressing was applied. Subcutaneous adipose tissue was obtained from the supragluteal region of the horse in the same surgery. The same orthopedic surgeon performed all surgeries.

\section{Post-surgery regime}

After induction of tendinopathy, horses were restricted to stall rest for 5 weeks ( 2 weeks after MSC injection) and then managed according to the rehabilitation protocol previously described [23].

The horses were checked 3 times a day using standardized pain scores until 10 days post-surgery. For pain relief, they received flunixin-meglumine (CP-Pharma Handelsgesellschaft mbH, Burgdorf, Germany), $1.1 \mathrm{mg} /$ $\mathrm{kg}$ but twice daily on the day of surgery and $0.55 \mathrm{mg} / \mathrm{kg}$ bwt twice daily on day 1 to 4 post surgery, followed by $0.55 \mathrm{mg} / \mathrm{kg}$ once daily on day 5 and 6 , as well as additional single $1.1 \mathrm{mg} / \mathrm{kg}$ bwt doses when required according to pain scoring results.

\section{Cell isolation and injection}

The adipose tissue was subjected to cell isolation by collagenase digestion and plastic-adherent cells were isolated and expanded as described previously [24]. The cells were cultivated in a standard culture medium with Dulbecco's Modified Eagle's Medium (DMEM, Life Technologies GmbH, Darmstadt, Germany), 20\% Fetal Bovine Serum (FBS, Sigma-Aldrich Chemie GmbH, Steinheim, Germany), $1 \%$ Penicillin $(10.000 \mathrm{IE} / \mathrm{ml}) /$ Streptomycin $(10.000 \mu \mathrm{g} / \mathrm{ml}$, Life Technologies $\mathrm{GmbH}$, Darmstadt, Germany) and 0,1\% Gentamicin (50 mg/ml, Life Technologies GmbH, Darmstadt, Germany). At passage 2 and 80\% confluency, MSC were labeled with SPIO particles (Molday ION Rhodamine $\mathrm{B}^{\mathrm{mi}}$, BioPAL, Inc. ${ }^{\mathrm{mm}}$, Worcester, MA, USA) at $25 \mu \mathrm{g}$ Fe per $\mathrm{ml}$ for $20 \mathrm{~h}$ and harvested. Part of the cells from each 
animal was used to confirm MSC characteristics such as trilineage differentiation and expression of CD29, CD44, CD90 and CD105 as described before [24, 25].

Three weeks after lesion induction (week 0), the freshly harvested and labeled MSC were injected into the lesions under ultrasonographic guidance. Horses were sedated and received an ulnar nerve block (forelimbs) or a high plantar nerve block (hindlimbs) with additional local anesthesia (Lidocain 2\%, bela-pharm GmbH \& Ko. KG, Vechta, Germany). With the horses standing, the skin was clipped and prepared aseptically. In a randomized manner, one hindlimb and one forelimb were injected with MSC $\left(10^{7}\right.$ cells in $1 \mathrm{ml}$ autologous serum) and the contralateral side with $1 \mathrm{ml}$ autologous serum. All injections were performed in a standardized procedure by the same veterinary surgeon blinded to the content of the syringes.

\section{Clinical and imaging evaluation}

Two veterinarians blinded for the treatment performed all examinations in a standardized procedure.

Clinical parameters comprised a palpation score and a lameness score. The palpation score included diffuse and local swelling, heat and pain to palpation, the total score points ranging from 4 (normal) to 16 (severe). The lameness score included weight bearing/lameness when standing, walking, trotting, and turning, the total score points ranging from 7 (normal) to 29 (severe).

Ultrasonographic examinations of the SDFT were performed using a $10 \mathrm{MHz}$ linear transducer (LOGIQ 5 Expert, GE Healthcare, Munich, Germany) with a standoff probe. The SDFT was divided into zones and at least one transverse and one longitudinal image was recorded at every level [26]. Echogenicity of the lesion, peritendinous edema and fiber pattern were evaluated for each zone by 2 blinded observers in consensus, using a semi quantitative score [27]. Furthermore, the cross-sectional areas of the tendon lesion and the whole tendon were measured in each transverse image and used to calculate the percentage of the tendon lesion.

MRI of the SDFT region was performed in the standing sedated horse using a 0.27 Tesla dedicated equine low-field MRI system (Hallmarq EQ2, Hallmarq Veterinary Imaging, Guildford, Surrey, UK). T2-weighted (T2w) fast spin echo sequences acquired in transverse plane at weeks $0,3,12$ and 24 were used to determine lesion signal and lesion areas. Lesion volume was approximated by multiplying the sum of the lesion areas in all images by $6 \mathrm{~mm}$ (5 mm slice thickness $+1 \mathrm{~mm}$ gap). Image processing was performed using Mathematica (Wolfram Research, Inc., Mathematica, Version 10.3.0.0, Champaign, IL). Tendon regions were manually drawn onto the images and converted into binary image masks. Background-corrected MRI images were segmented, and segmentations were multiplied with the corresponding binary image masks to detect lesion areas within the tendons. Positive regions in the resulting binary images were smoothed and final binary lesion masks were obtained. Grayscale values for tendon and lesion regions were extracted from the backgroundcorrected images using the generated masks.

For all parameters obtained from ultrasonographic images as well as lesion signal intensity obtained from MRI images, mean values of images obtained from the different tendon levels were calculated and used for further analysis, in order to account for the proximo-distal dimensions of the lesions.

\section{Collection of tendon samples}

Three weeks after MSC injection, tendon biopsies of the maximum lesion, which had been identified by MRI before, were taken from the hindlimbs under general anesthesia. The tendon was approached via a skin incision of $3 \mathrm{~cm}$ and $0.2 \times 0.3 \times 2 \mathrm{~cm}$ tendon tissue was collected and fixed in paraformaldehyde (Carl Roth, Karlsruhe, Germany) for histological examination. Tendon, peritendineum, subcutis and skin were sutured, and dressings were applied. Post-operative management and pain medication were performed as described above. After taking this biopsy, the hindlimbs were excluded from all further assessments.

24 weeks after MSC injection, the animals were euthanized in general anesthesia using Romifidin $0,06 \mathrm{mg} / \mathrm{kg}$ bwt i.v. (Sedivet ${ }^{\circ}, 10 \mathrm{mg} / \mathrm{ml}$, Boehringer Ingelheim Vetmedica $\mathrm{GmbH}$, Ingelheim am Rhein, Germany) and Butorphanol 0,03 mg/kg but i.v (Alvegesic ${ }^{\circ}, 10 \mathrm{mg} / \mathrm{ml}$, CP-Pharma Handelsgesellschaft $\mathrm{mbH}$, Burgdorf, Germany) for sedation, Diazepam $0,08 \mathrm{mg} / \mathrm{kg}$ bwt i.v. (Diazepam- ${ }^{\circ}$ Lipuro, $5 \mathrm{mg} / \mathrm{ml}$, B. Braun Melsungen AG, Melsungen, Germany) and Ketamin 2,2 mg/kg bwt i.v (Ursotamin ${ }^{\circ}, 100 \mathrm{mg} / \mathrm{ml}$, Serumwerk Bernburg AG, Bernburg, Germany) for the induction of anesthesia and T61 $6 \mathrm{ml} / 50 \mathrm{~kg}$ bwt i.v. (Intervet Deutschland $\mathrm{GmbH}$, Unterschleißheim, Germany) for euthanasia. The whole metacarpal region of both forelimb SDFT was collected. First, macroscopic evaluation was performed, at which all parameters (swelling, edema, adhesions, redness) were summarized in a score ranging from 0 (normal) to 15 (severe). Afterwards, the tendons were sectioned into $2 \mathrm{~cm}$ long pieces, of which the lateral part was fixed in paraformaldehyde for histological examination and the medial part was frozen for gene expression analysis.

\section{Histology}

For histological examination, $3 \mu \mathrm{m}$ paraffin sections were prepared from the hindlimb biopsies and from the forelimb tendons, stained and assessed as described below. Regarding the forelimb tendons, unless stated otherwise, mean values were calculated from all dissected tendon 
pieces, representing the whole metacarpal region including proximal and distal healthy areas, for further analysis.

The parameters evaluated in hematoxylin-eosin (HE) staining were polymorphonuclear leukocytes, lymphocytes, macrophages, perivasculitis, necrosis, edema, calcification, collagen disposition, fibrinosis and fiber organization. The microscopic assessment was done by a blinded veterinary pathologist, the score ranging from 0 (normal) to 30 (severe) as described before [28].

Masson's Trichrome staining was used for evaluation of the percentage of Fuchsin staining corresponding to uninjured or regenerated tendon regions [29]. The percentages of Fuchsin-stained red areas were measured based on whole slide scans obtained in a slide scanner (Pannoramic SCAN, 3DHISTECH, Budapest, Hungary). Red and blue color channels were extracted from the acquired images and respective stained regions were segmented by the Kittler-Illingworth minimum error thresholding method using Mathematica software [30].

Picrosirius red staining and polarized light microscopy were used to assess the occurrence of crimp. Three images from randomly chosen fields of view were obtained per slide using a 10× objective (Olympus BX41 Laboratory microscope equipped with a U-pot drop in polarizer; Olympus GmbH, Hamburg, Germany). The percentages of large crimp ( $>15 \mu \mathrm{m}$ distance) representing healthy, mature crimp, or small and no crimp (< $15 \mu \mathrm{m}$ distance) representing immature or missing crimp were measured manually by 2 blinded investigators using ImageJ open source software.
DAPI (4',6-diamidino-2-phenylindole, Carl Roth $\mathrm{GmbH}+\mathrm{Co}$. KG, Karlsruhe, Germany) nuclear staining was used to evaluate cellularity based on the nucleated cell fraction. Whole slide scans from the maximum lesion levels were obtained in the slide scanner evaluated in analogy to the Masson's Trichrome stained slides. The occurrence of nucleated cells represented by the percentage of blue staining (DAPI filter channel) was determined relative to the total area of each section. Similarly, as an indicator for vascularization, the occurrence of erythrocytes was calculated as the percentage of red fluorescence (Rhodamine filter channel), representing erythrocyte autofluorescence, per total section area.

Collagen I immunohistochemical staining was performed on representative sections from the proximal lesion, maximum lesion, and distal lesion for each forelimb tendon and one section of each hindlimb biopsy. Staining was done with anti-collagen I antibody (rabbit polyclonal, Abcam, Cambridge, UK) and a detection kit (EXPOSE Mouse and Rabbit Specific AP, Abcam) according to the manufacturer's instructions. Two blinded investigators evaluated the absence or presence of collagen I with 0 representing absence, 1 representing mild and 2 representing marked presence of immunostaining.

\section{Musculoskeletal marker expression}

Musculoskeletal marker expression was analyzed by real-time reverse-transcription polymerase chain reaction (RT-PCR) in each forelimb tendon sample piece.

Table 1 Primers used for RT-PCR analysis of musculoskeletal marker expression

\begin{tabular}{|c|c|c|c|}
\hline Gene & Primer pair sequences & GenBank accession number & PCR product in bp \\
\hline \multirow[t]{2}{*}{ ACTB } & For: ATCCACGAAACTACCTTCAAC & NM_001081838.1 & 174 \\
\hline & Rev: CGCAATGATCTTGATCTTCATC & & \\
\hline \multirow[t]{2}{*}{ GAPDH } & For: TGGAGAAAGCTGCCAAATACG & NM_001163856.1 & 309 \\
\hline & Rev: GGCCTTTCTCCTTCTCTTGC & & \\
\hline \multirow[t]{2}{*}{ Collagen $1 \mathrm{~A} 2$} & For: CAACCGGAGATAGAGGACCA & XM_001492939.1 & 243 \\
\hline & Rev: CAGGTCCTTGGAAACCTTGA & & \\
\hline \multirow[t]{2}{*}{ Collagen 2A1 } & For: ATTGTAGGACCCAAAGGACC & XM_001496152 & 199 \\
\hline & Rev: CAGCAAAGTTTCCACCAAGG & & \\
\hline \multirow[t]{2}{*}{ Collagen 3A1 } & For: AGGGGACCTGGTTACTGCTT & XM_001917620.2 & 216 \\
\hline & Rev: TCTCTGGGTTGGGACAGTCT & & \\
\hline \multirow[t]{2}{*}{ Decorin } & For: ACCCACTGAAGAGCTCAGGA & NM_001081925.2 & 239 \\
\hline & Rev: GCCATTGTCAACAGCAGAGA & & \\
\hline \multirow[t]{2}{*}{ Tenascin-C } & For: CTAGAGTGTCTCACTATCAGG & XM_001916622.2 & 163 \\
\hline & Rev: CTAGAGTGTCTCACTATCAGG & & \\
\hline \multirow[t]{2}{*}{ Scleraxis } & For: TACCTGGGTITCTTCTGGTCACT & NM_001105150.1 & 51 \\
\hline & Rev: TATCAAAGACACAAGATGCCAGC & & \\
\hline \multirow[t]{2}{*}{ Osteopontin } & For: TGAAGACCAGTATCCTGATGC & XM_001496152 & 158 \\
\hline & Rev: GCTGACTTGTTTCCTGACTG & & \\
\hline
\end{tabular}




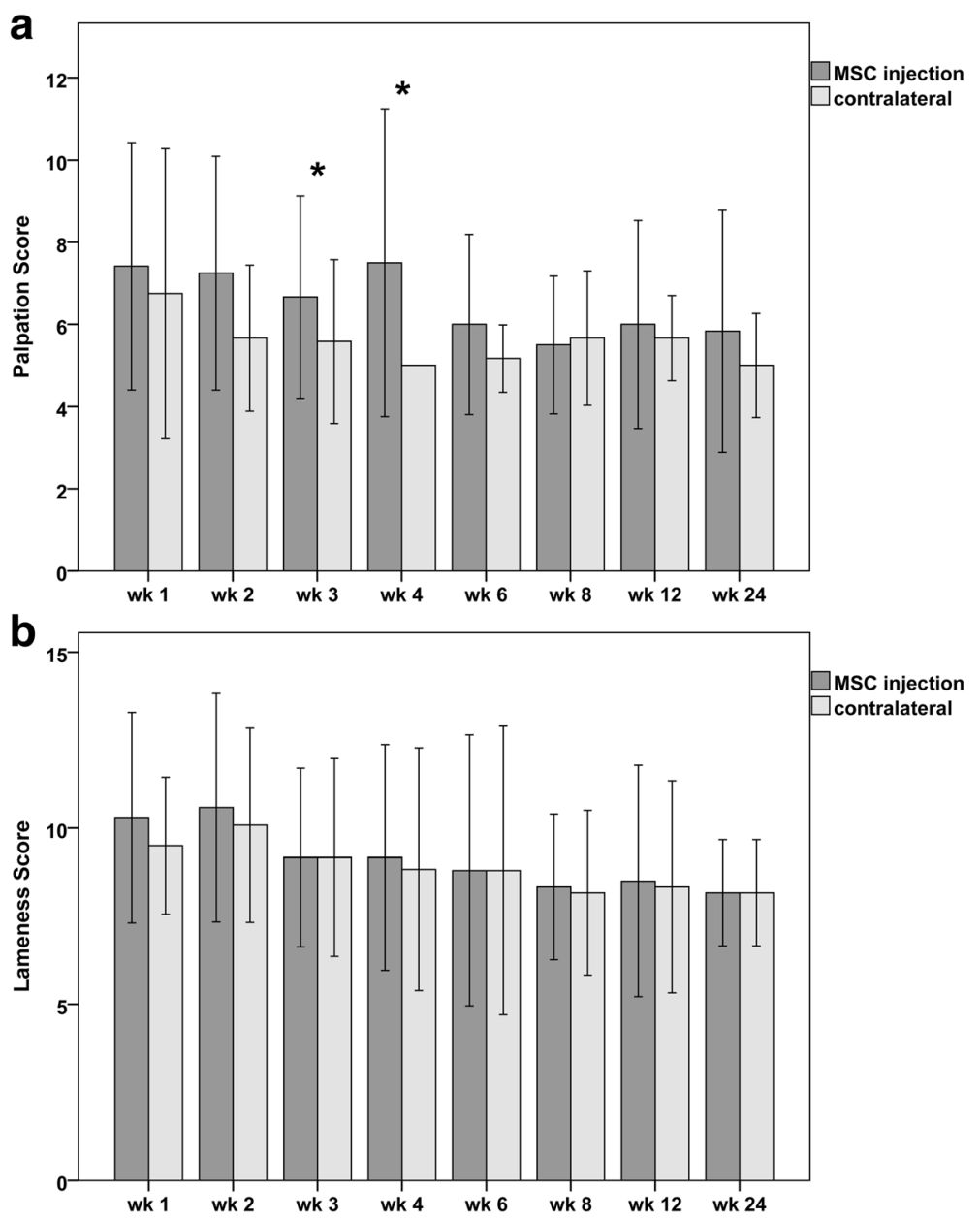

Fig. 1 Clinical parameters: Diagrams displaying mean $( \pm 2$ SD) values of a palpation score and $\mathbf{b}$ lameness score over the whole follow-up period; stars indicate significant differences between MSC-injected and contralateral tendons $(p<0.05)$; wk.: week post MSC injection

Mean values, representing the whole metacarpal region of the tendon, were used for further analysis.

Frozen tendon samples were homogenized, and total RNA was isolated, purified and transcribed into cDNA using the RevertAid H Minus First Strand cDNA Synthesis Kit (Thermo Fisher Scientific). RT-PCR was performed with a 7500 Real Time PCR System (Applied Biosystems, Foster City, USA) as described previously [31]. Primers used are listed in Table 1, ACTB and GAPDH were used as housekeeping genes for relative quantification [32].

\section{Statistical analysis}

Using SPSS 20 statistics software (IBM, Ehningen, Germany), Shapiro-Wilk tests were executed to test the hypothesis of normal distribution of data. If this hypothesis was not rejected, paired t-tests were performed to compare MSC-treated tendons with the contralateral controls, otherwise Wilcoxon-tests were performed. $P$-values $<0.05$ were considered significant.

\section{Results}

Clinical and imaging results

Induction of tendon lesions was demonstrable in all tendons. No significant differences between the left and right tendons were observed prior to cell injection, neither clinically nor in imaging. The procedures, including the recovery from tendon biopsies, were tolerated well using the medication described above.

During the first 2 weeks after cell injection, no significant differences could be detected between the two groups. However, there was a tendency that the MSC-injected tendons showed prolonged clinical signs of inflammation including swelling, heat, and pain. This became manifest in the palpation scores, which remained higher in the MSC group until week 6 , with the difference being significant at weeks $3(p=0.015)$ and $4(p=0.022)$ (Fig. 1). Correspondingly, as seen in ultrasonography, in the MSC group, the cross-sectional area of the tendon was higher at weeks $3(p=0.016)$ and $4(\mathrm{p}=0.022)$, the percentage of the tendon lesion was 

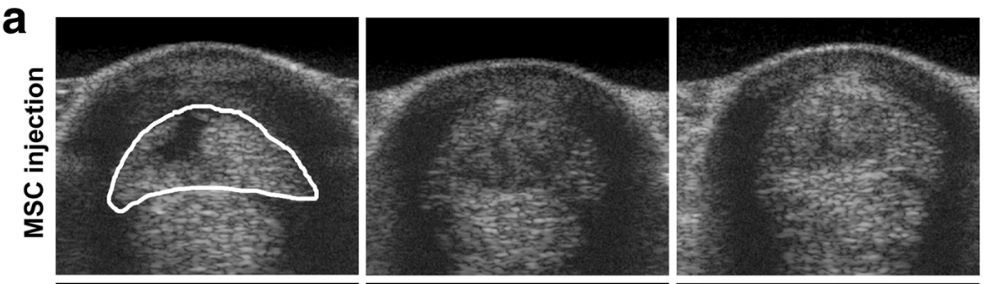

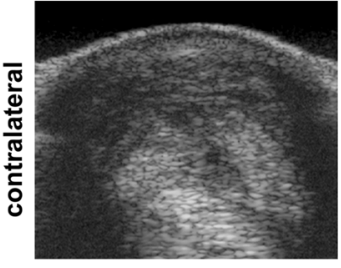

wk 3

b
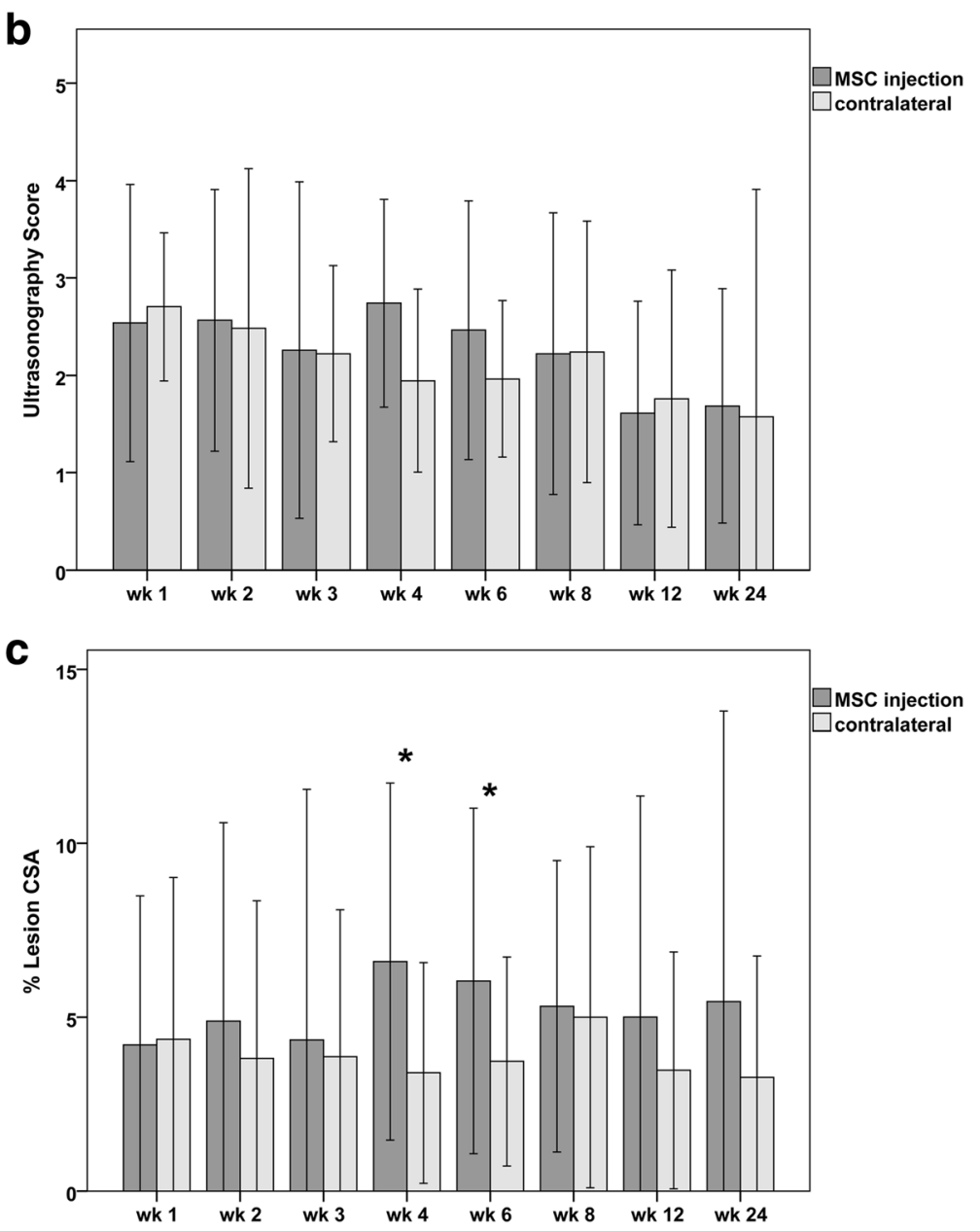

Fig. 2 Ultrasonographic parameters: a representative transverse images obtained from the MSC-injected and the contralateral superficial digital flexor tendons 3, 12 and 24 weeks after MSC injection; the respective tendon is indicated by the white line in the first upper image; note the hypoechoic (dark) lesions within the tendons, which are decreasing over time. Diagrams displaying mean ( \pm 2 SD) values of $\mathbf{b}$ ultrasonography score and $\mathbf{c}$ percentage of the lesion within the cross-sectional area (CSA) of the tendon over the whole follow-up period; stars indicate significant differences between MSC-injected and contralateral tendons $(p<0.05)$; wk.: week post MSC injection 
a
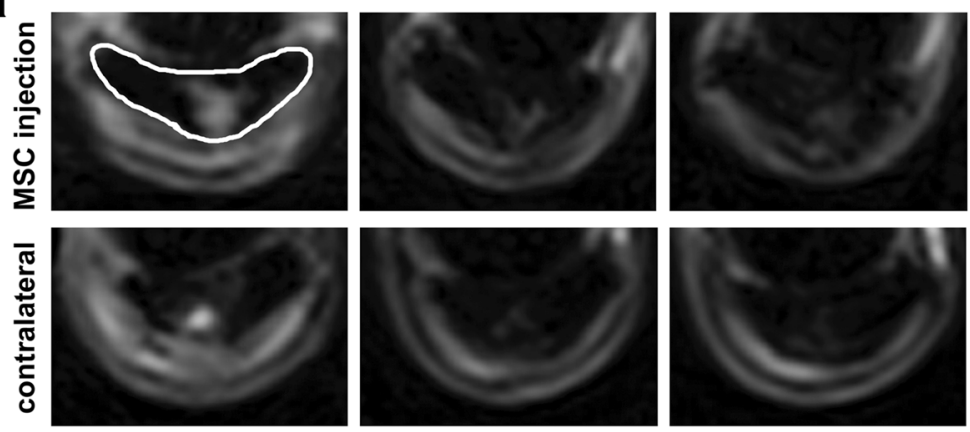

wk 3

wk 12

wk 24

b

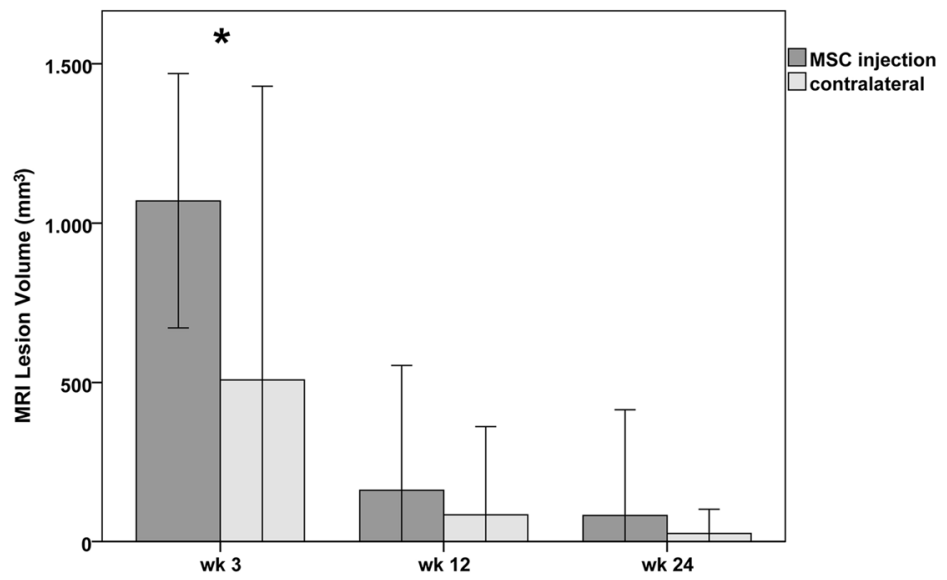

C

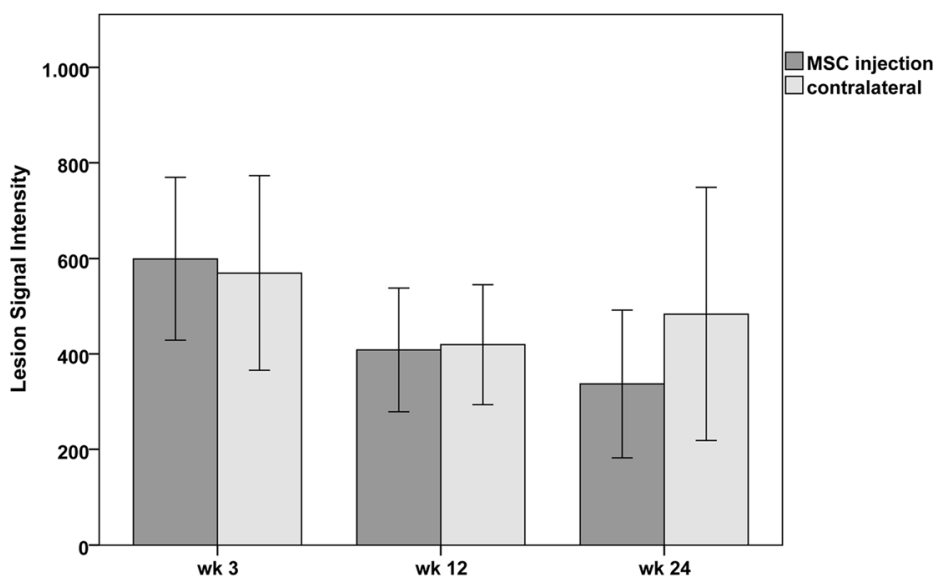

Fig. 3 Magnetic resonance imaging parameters: a representative transverse T2-weighted images obtained from the MSC-injected and the contralateral superficial digital flexor tendons 3,12 and 24 weeks after MSC injection; the respective tendon is indicated by the white line in the first upper image; note the lesions within the tendons, displaying high signal intensity at week 3, which is decreasing over time. Diagrams displaying mean $\left( \pm 2\right.$ SD) values of $\mathbf{b}$ lesion volume determined based on MRI images in $\mathrm{mm}^{3}$ and $\mathbf{c}$ lesion signal intensity obtained from MRI images; star indicates significant difference between MSC-injected and contralateral tendons $(p<0.05)$; wk.: week post MSC injection; at week 24 , instead of $n=6$ tendons per group, only 2 tendons are shown in the MSC group and 3 in the contralateral control group, due to the fact that the remaining lesions were not detected anymore

higher at weeks $4(p=0.042)$ and $6(p=0.039)$, and the mean ultrasonography scores were higher at weeks 4 and 6, although the latter was not significant (Fig. 2). In MRI, lesion volume at week 3 was higher in the MSC group $(p=0.02)$ (Fig. 3).
However, after the first weeks, the clinical and imaging findings improved and were more similar in both groups. At week 24, based on the T2-weighted MRI image series, the tendon lesions had resolved in 4 out of 6 cases in the MSC group and in 3 out of 6 cases in 

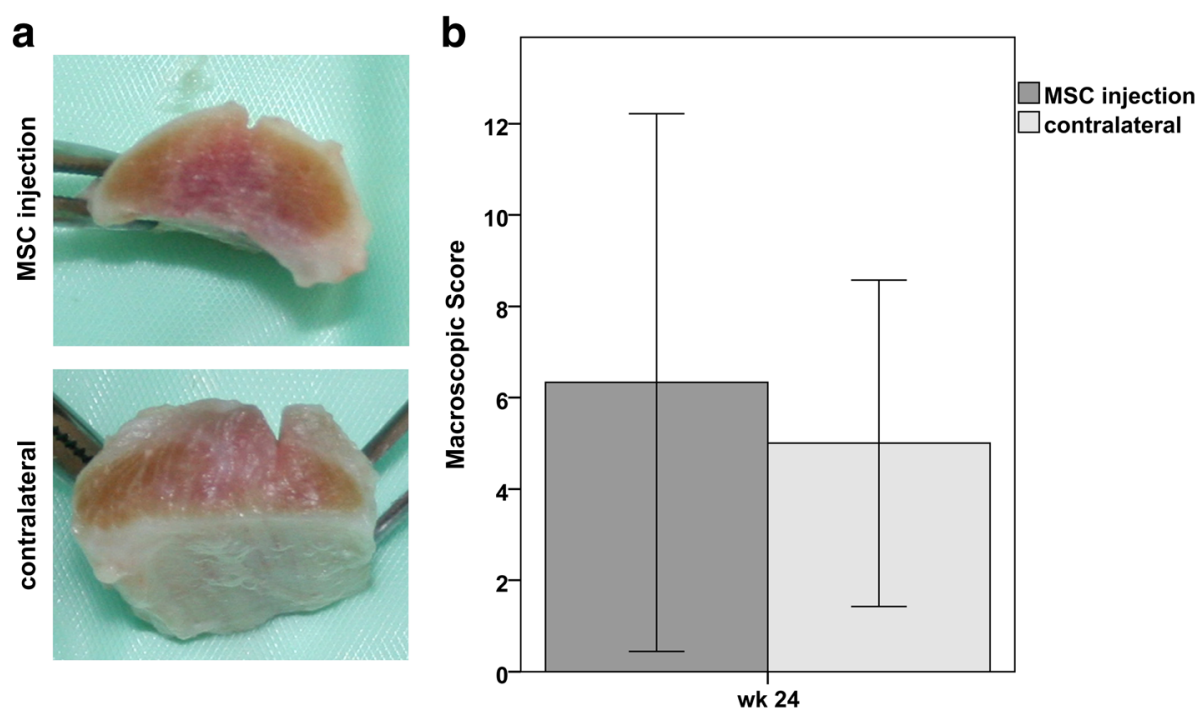

Fig. 4 Macroscopic parameters: a representative images of the dissected superficial digital flexor tendons at maximum lesion level, displaying reddish and whitish injured areas within the tendon cross-section and $\mathbf{b}$ diagram displaying mean $( \pm 2 \mathrm{SD})$ values of score points obtained at macroscopic assessment; wk.: week post MSC injection

the control group. In the remaining lesions, the mean lesion signal intensity was lower in the MSC group, suggesting better tendon healing. Further clinical or imaging parameters did not indicate improvement compared to the controls. Correspondingly, macroscopic assessment after euthanasia did not reveal any significant differences (Fig. 4).

\section{Histology}

Histologic findings largely reflected the clinical and imaging findings.

At week 3, hindlimb biopsies displayed a more frequent occurrence of macrophages and perivasculitis, resulting in a higher $\mathrm{HE}$ score, a lower percentage of healthy crimp and a higher percentage of erythrocytes in the MSC group, suggesting increased inflammation and vascularization. However, these differences were not significant, and the percentage of Fuchsin staining, the percentage of nuclei as well as collagen I immunostaining were similar in both groups (Fig. 5).

At week 24, such differences did not exist anymore, most stainings and parameters assessed being similar in both groups (Fig. 6). However, the percentage of nuclei was lower in the MSC group $(p=0.022)$, reflecting lower cellularity (Fig. 5).

\section{Musculoskeletal marker expression}

All tendon markers including collagen 1A2, collagen $3 \mathrm{~A} 1$, decorin, tenascin- $\mathrm{C}$ and scleraxis, as well as the $\mathrm{pu}-$ tative early osteogenic marker osteopontin, were expressed at detectable but variable levels (Fig. 7). Collagen 2A1 was not expressed at detectable levels. No significant differences could be observed between both groups.

\section{Discussion}

Only few differences in tendon healing could be found between MSC and control group at week 24. Differences included that lesion resolution, as seen in T2w MRI, was more advanced and cellularity was lower in MSC-treated tendons at week 24. Furthermore, a transient increase in inflammatory reaction and lesion size was observed in the MSC-treated tendons during the first weeks. However, at week 24, clinical parameters, ultrasound, macroscopic and histological scores as well as musculoskeletal marker expression were not different between treated and control tendons. Based on the fact that MSC had engrafted within the tendon lesions [22] and having designed this study with a relatively long follow-up of 24 weeks, more significant differences between the two groups had been expected based on the previous literature. Yet, the current data fail to provide distinctive evidence to support the hypothesis that MSC improve tendon healing.

The therapeutic approach pursued in the current study was to locally inject adipose-derived MSC 3 weeks after the induction of the tendon lesions. Applying the MSC 3 weeks after induction of the lesion is realistic, because neither in human nor in equine medicine, the patient would receive this autologous therapy within days after the first onset of tendinopathy. Furthermore, the time frame of 3 weeks between induction and treatment should be adequate to support tendon healing, as Crovace et al. found better histological results in the treated groups after 

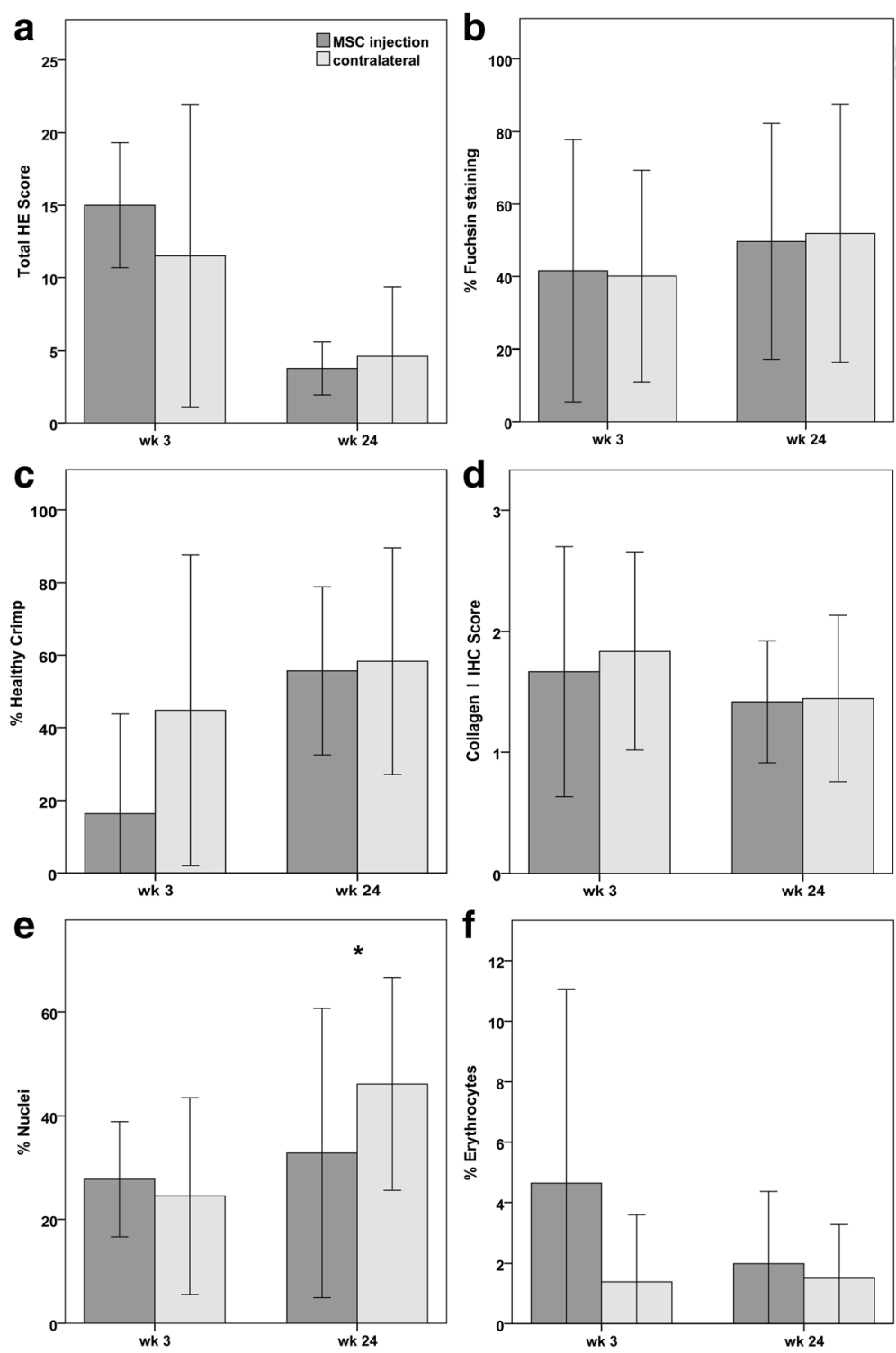

Fig. 5 Histology parameters: Diagrams displaying mean $( \pm 2$ SD) values of a score points obtained at evaluation of hematoxylin-eosin (HE) stained slides, $\mathbf{b}$ percentage of fuchsin staining representing uninjured or regenerated tendon tissue, $\mathbf{c}$ percentage of areas displaying healthy crimp, $\mathbf{d}$ intensity of collagen I immunohistochemical (IHC) staining, e percentage of DAPI-stained nuclei indicating cellularity and $\mathbf{f}$ percentage of erythrocytes indicating vascularization; star indicates significant difference between MSC-injected and contralateral tendons $(p<0.05)$; wk.: week post MSC injection

choosing an interval of 3 weeks as well [28]. The latter as well as most other studies in horses were conducted with bone marrow-derived MSC [11, 16, 28, 33]. However, the potential of adipose-derived cells is increasingly recognized [34] and adipose-derived cells have also been used for regenerative therapy of tendon lesions with good results [35, 36]. Furthermore, Burk et al. have shown that adipose-derived MSC might be superior to bone marrow-derived MSC regarding their potential to positively influence tendon matrix reorganization [37]. Therefore, the decision to use adipose-derived MSC was favorable, as adipose tissue is easily available with minor surgery in both horses and humans compared to bone marrow, and it remains unlikely that this cell source is the reason for the absence of more significant improvements.

However, the MSC used in the current study had been labeled with SPIO, aiming to track the injected cells and monitor their contribution to tendon healing at the same time. Favorably, these SPIO-labeled MSC have been demonstrated to integrate at the site of intralesional injection [22], in accordance with a similar recent study [38]. It has also been shown in vivo and in vitro that SPIO labeling influences neither stemness nor viability nor proliferation of stem cells [39-42]. In an ovine osteoarthritis model using 


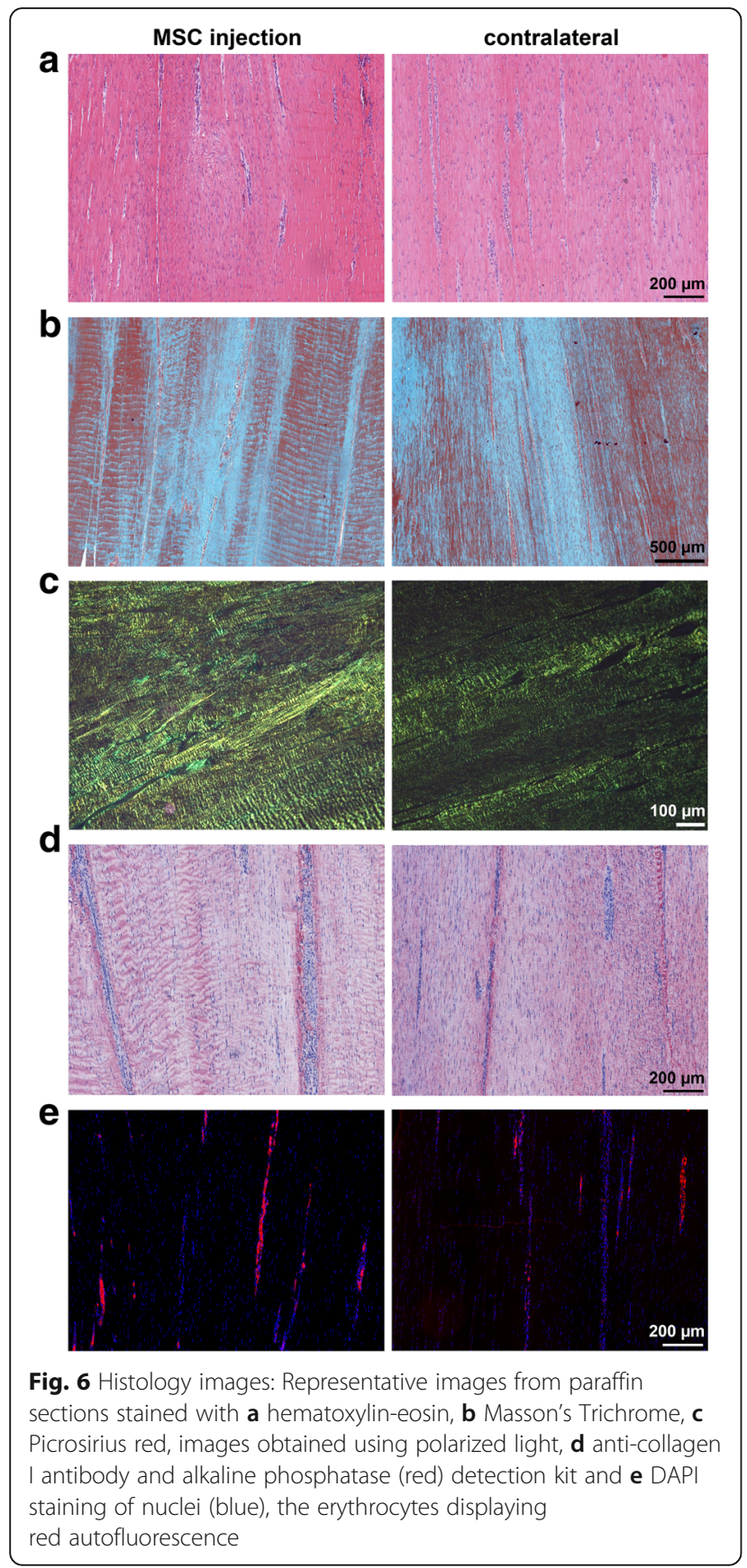

SPIO-labeled as well as SPIO-negative control MSC, no adverse side effects of SPIO-labeled MSC have been demonstrated [43]. However, current literature also suggests that SPIO influences immune reactions in the surrounding tissue and inhibits endothelial nitric oxide synthase [44, 45]. Therefore, it cannot be excluded that SPIO-labeling of the MSC used in the current study might have compromised their regenerative capacity and/or that released SPIO particles have triggered inflammation.

In this study, the tendon defect was created by a low dose of collagenase injected with a $11 \mathrm{G}$ bone marrow aspiration needle. This large needle creates a mechanical defect in addition to the enzymatical defect. The rationale behind this approach was to combine the advantages of the two most commonly used techniques, collagenase injection and surgical induction, mimicking natural core lesions more closely $[46,47]$. This defect is therefore different from those in other studies using higher doses of collagenase and ultrasound-guided injection via smaller needles [28, 33, 48], which is likely to impact on responsiveness to MSC treatment.

Furthermore, the inclusion of adequate controls is crucial. In this study, we chose to use the contralateral tendons as intra-individual controls and to inject these tendons with serum, as serum was used as vehicle to deliver the MSC in the treatment group. The vehicle for MSC delivery should ideally maintain MSC viability prior to injection and support their regenerative effect. While for bone marrow MSC, bone marrow supernatant is most commonly used, serum is a good alternative for other MSC sources. However, saline or phosphate buffered saline (PBS) have frequently been chosen for injection into the control tendons [11,33,36], which is not indicative as to whether any observed effect is due to MSC treatment or the delivery vehicle. In this line, Geburek et al. used autologous conditioned serum (ACS) without MSC for treatment of naturally occurring tendinopathy and reported on significant reduction of lameness and swelling in the ACS group compared to saline [17]. This suggests that serum itself may have beneficial effects on tendon healing. Consequently, differences found in studies using PBS or saline for control injections but serum or bone marrow supernatant as MSC delivery vehicle $[11,33,36]$ cannot without doubt be attributed solely to the MSC. This could partly explain that fewer beneficial effects were detected in the current study, in which serum was used as a more rigorous control regarding MSC efficacy.

The use of the contralateral tendon of the same animal as control limits interference of inter-individual differences with the results, reduces the numbers of animals required, and has been described by several groups [28, 33, 38]. However, MSC could enter the blood circulation after injection and migrate to other sites of injury or inflammation as well, e.g. the contralateral defect, a process referred to as homing $[49,50]$. MSC have been shown to circulate in peripheral blood after intralesional injection but had not been found in untreated lesions so far [51, 52]. Yet, in the previously published part of the current study, MSC could be shown to be present in the contralateral tendon lesions as well, albeit in small numbers [22]. Based on that, the effect of MSC distribution after intralesional injection might have been underestimated when the current study was designed. However, we still consider a strong impact on the results as unlikely, as significantly fewer cells were found in the control lesions compared to the treated lesions. 

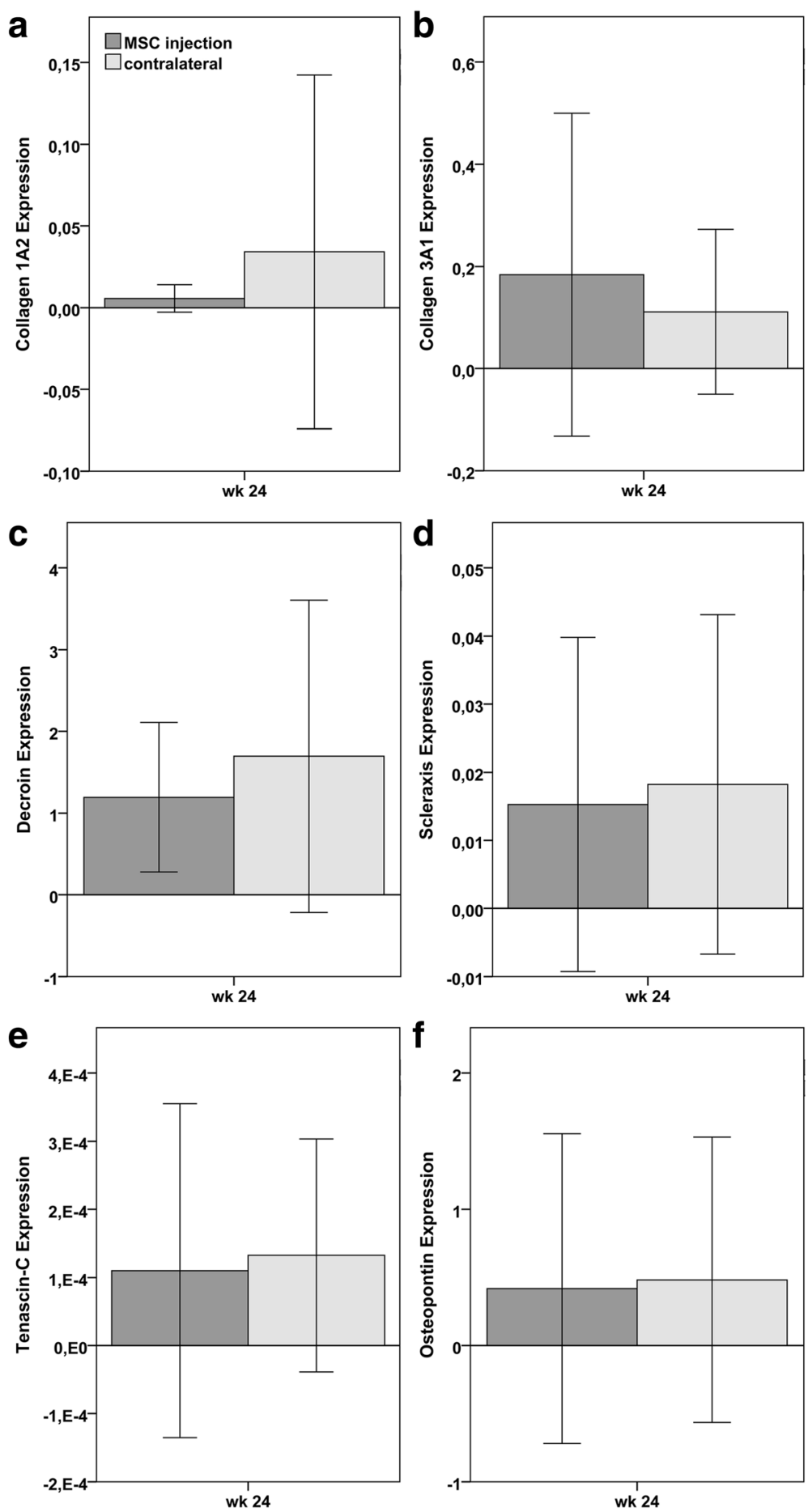

Fig. 7 Gene expression: Diagrams displaying mean ( \pm 2 SD) values of relative gene expression of a collagen 1A2, b collagen 3A1, c decorin, d scleraxis, e tenascin-C and $\mathbf{f}$ osteopontin, 24 weeks (wk) after MSC injection

Regarding sample and data analysis, while other studies used only the maximum lesion zone for imaging assessment and the macroscopically affected areas of the tendon for histological examination [28, $33,48]$, we analyzed the whole metacarpal area of the tendon. This may have hampered the detection of differences potentially existing at the maximum lesion sites only. However, this method is more rigorous as it takes the whole longitudinal extension of the defect into account, and there is no potential bias as 
subjective identification of maximum lesion site is not required.

Possibly elucidating which of the discussed factors and differences between studies might most likely explain the outcome, two previous studies are particularly interesting for comparison. A recent carefully designed study, investigating the effect of autologous adipose-derived MSC suspended in inactivated serum in surgically created tendon lesions in the horse, over a follow-up period of 22 weeks, also revealed few improvements. The authors did not find significant differences in histology, biochemical or biomechanical parameters between MSC-treated lesions and serum-injected contralateral control tendon lesions, although hydroxylysylpyridinoline content in the MSC group was closer to that of healthy tendon tissue, potentially indicating better crosslinking [38]. In a different study, the effect of bone marrow-MSC suspended in bone marrow supernatant for treatment of naturally occurring tendon lesions was investigated. After a follow-up of 6 months post injection, treatment outcome was favourable, with improved tissue structure, lower cellularity, vascularity, water and glycosaminoglycan content as well as matrix metalloproteinase-13 activity. While it should be considered that controls were based on saline injections, this study stands out because naturally occurring tendon lesions were used, instead of artificially creating them [11].

Considering the outcome of these two studies in line with the current results, it appears most likely that MSC are not capable to repair mechanically induced tendon lesions, potentially due to the associated loss of tissue that cannot be replaced adequately over a follow-up period of 22 or 24 weeks, respectively. The choice of the animal model is crucial in clinical translation and can strongly impact on the results of preclinical studies. Although we aimed to overcome the limitations of collagenase-based and surgical lesion induction by combining mild approaches of both techniques, the current model might still not reflect naturally occurring tendinopathy. Therefore, taking advantage of the fact that horses are equally prone to natural tendon disease as humans, to use them as natural models as reported by Smith et al. still represents the most reliable option- albeit not without challenges [11]. With equal importance, it remains possible that MSC are not significantly more effective than delivery vehicles such as bone marrow supernatant or serum, even if inactivated, indicating that this fundamental question has yet to be answered.

Yet, we observed significant differences during the early healing phase between weeks 3 and 6 , at which clinical assessment and imaging suggested a stronger but transient inflammatory reaction in MSC-treated tendons. Although based on the current data, it cannot be excluded that SPIO might have induced this inflammatory response, our results correspond to a previous study, in which a transient increase in vascularization after injection of MSC was observed, while the latter were not labeled with SPIO [35]. This could be part of the immunomodulatory effects of MSC, which could be important for debridement and lesion resolution and to prevent fibrotic repair, thus there is reason to consider that this transient inflammatory reaction could be beneficial [53]. However, except for the lower cellularity of treated tendons, no distinctive evidence to support this hypothesis was found in this study, thus further studies need to elucidate the immunomodulatory effects of MSC in tendon healing.

\section{Conclusions}

Intralesional injection of adipose-derived MSC led only to minor improvements of tendon healing within the observed time frame of 24 weeks, indicating that MSC were not capable of repairing the mechanically disrupted tissue within the tendon lesions during the observed period. Future studies, ideally based on using naturally occurring tendon lesions as a model and using the adequate controls, still have to answer the fundamental question whether the effect of MSC is superior to that of biologically active body fluids such as serum. However, we observed that MSC induced a transient inflammation during early healing, followed by reduced cellularity in treated tendons at week 24 , which suggests a modulatory effect warranting further investigations.

\section{Abbreviations \\ ACS: Autologous Conditioned Serum; ACTB: Actin Beta; BMBF: German Federal Ministry of Education and Research; CDNA: Complementary \\ Deoxyribonucleic Acid; cm: Centimeters; DAPI: 4',6-diamidino-2-phenylindole; DMEM: Dulbecco's Modified Eagle's Medium; EMA: European Medicines Agency; FBS: Fetal Bovine Serum; FDA: Food and Drug Administration; Fe: Iron (Ferrum); G: Gauge; GAPDH: Glyceraldehyde 3-phosphate dehydro- genase; HE: Hematoxylin-Eosin; IHC: Immunohistochemical; IU: International Unit; mg/kg bwt: Milligrams per Kilogram body weight; ml: Milliliters; mm: Millimeters; MRI: Magnetic Resonance Imaging; MSC: Mesenchymal stromal cells; PBS: Phosphate Buffered Saline; RNA: Ribonucleic Acid; RT- PCR: Real-time reverse-transcription polymerase chain reaction; SD: Standard Deviation; SDFT: Superficial Digital Flexor Tendon; SMWK: Saxon Ministry of Science and the Fine Arts; SPIO: Superparamagnetic Iron Oxide; T2w: T2- weighted; US: Ultrasound; wk: Week}

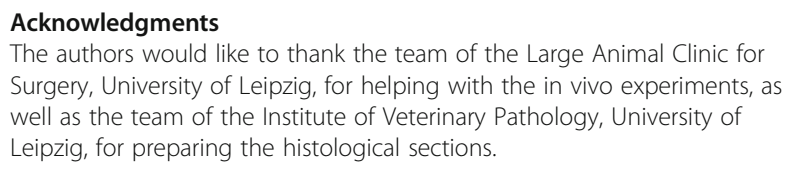
Surgery, University of Leipzig, for helping with the in vivo experiments, as well as the team of the Institute of Veterinary Pathology, University of Leipzig, for preparing the histological sections.

\section{Funding}

The work presented in this paper was made possible by funding from the German Federal Ministry of Education and Research (BMBF 1315883) and the Saxon Ministry of Science and the Fine Arts (SMWK). We acknowledge support from the German Research Foundation (DFG) and Leipzig University within the program of Open Access Publishing.

Availability of data and materials

The datasets used and/or analysed during the current study are available from the corresponding author on reasonable request. 


\section{Authors' contributions}

$\mathrm{ABA}, \mathrm{CH}$ and JB made substantial contributions to research design, acquisition, analysis, and interpretation of data, to drafting the paper and revising it critically. DB, CG, AH and SS made substantial contributions to acquisition and interpretation of data and to revising the paper critically. WB and $\mathrm{CJ}$ made substantial contributions to research design and to revising the paper. GR and KW made substantial contributions to analysis and interpretation of data and to revising the paper critically. All authors read and approved the final manuscript

\section{Ethics approval and consent to participate}

Approval of the local ethics committee (Landesdirektion Leipzig, TW 34/13) had been given beforehand. No human participants have been involved.

\section{Consent for publication}

Not applicable.

\section{Competing interests}

The authors declare that they have no competing interests.

\section{Publisher's Note}

Springer Nature remains neutral with regard to jurisdictional claims in published maps and institutional affiliations.

\section{Author details}

'Department of Orthopedics, Traumatology and Plastic Surgery, University of Leipzig, Liebigstr. 20, 04103 Leipzig, Germany. ${ }^{2}$ Translational Center for Regenerative Medicine (TRM), University of Leipzig, Leipzig, Germany. ${ }^{3}$ Saxon Incubator for Clinical Translation (SIKT), University of Leipzig, Leipzig, Germany. ${ }^{4}$ University Equine Hospital, University of Leipzig, Leipzig, Germany. ${ }^{5}$ Department of Clinical Science and Services, The Royal Veterinary College, University of London, London, UK. ${ }^{6} \mathrm{~S} c h o o l$ of Biosciences and Veterinary Medicine, University of Camerino, Camerino, Italy. Institute of Veterinary Physiology, University of Leipzig, Leipzig, Germany. ${ }^{8}$ Institute of Anatomy, Medical Faculty, University of Leipzig, Leipzig, Germany. ${ }^{9}$ Department of Biotechnology, University of Natural Resources and Life Sciences, Vienna, Austria.

\section{Received: 27 February 2018 Accepted: 28 June 2018}

\section{Published online: 18 July 2018}

\section{References}

1. de Jonge S, van den Berg C, de Vos RJ, van der Heide HJL, Weir A, Verhaar $J A N$, et al. Incidence of midportion Achilles tendinopathy in the general population. Br J Sports Med. 2011;45:1026-8.

2. Alfredson $\mathrm{H}$. Ultrasound and Doppler-guided mini-surgery to treat midportion Achilles tendinosis: results of a large material and a randomised study comparing two scraping techniques. Br J Sports Med. 2011:45:407-10.

3. de Jonge S, de Vos RJ, Weir A, van Schie HTM, Bierma-Zeinstra SMA, Verhaar JAN, et al. One-year follow-up of platelet-rich plasma treatment in chronic Achilles tendinopathy: a double-blind randomized placebo-controlled trial. Am J Sports Med. 2011;39:1623-9.

4. Sadoghi P, Rosso C, Valderrabano V, Leithner A, Vavken P. The role of platelets in the treatment of Achilles tendon injuries. J Orthop Res Off Publ Orthop Res Soc. 2013:31:111-8.

5. Willberg L, Sunding K, Ohberg L, Forssblad M, Fahlström M, Alfredson H. Sclerosing injections to treat midportion Achilles tendinosis: a randomised controlled study evaluating two different concentrations of Polidocanol. Knee Surg Sports Traumatol Arthrosc Off J ESSKA. 2008;16:859-64.

6. Vannini F, Di Matteo B, Filardo G, Kon E, Marcacci M, Giannini S. Platelet-rich plasma for foot and ankle pathologies: a systematic review. Foot Ankle Surg Off J Eur Soc Foot Ankle Surg. 2014;20:2-9.

7. Kearney RS, Parsons N, Metcalfe D, Costa ML. Injection therapies for Achilles tendinopathy. Cochrane Database Syst Rev. 2015;(5):CD010960.

8. Filardo G, Di Matteo B, Kon E, Merli G, Marcacci M. Platelet-rich plasma in tendon-related disorders: results and indications. Knee Surg Sports Traumatol Arthrosc. 2018;26(7):1984-99.

9. Avella CS, Ely ER, Verheyen KLP, Price JS, Wood JLN, Smith RKW. Ultrasonographic assessment of the superficial digital flexor tendons of National Hunt racehorses in training over two racing seasons. Equine Vet J. 2009:41:449-54.
10. Patterson-Kane JC, Becker DL, Rich T. The pathogenesis of tendon microdamage in athletes: the horse as a natural model for basic cellular research. J Comp Pathol. 2012;147:227-47.

11. Smith RKW, Werling NJ, Dakin SG, Alam R, Goodship AE, Dudhia J. Beneficial effects of autologous bone marrow-derived mesenchymal stem cells in naturally occurring tendinopathy. PLoS One. 2013:8:e75697.

12. Williams RB, Harkins LS, Hammond CJ, Wood JL. Racehorse injuries, clinical problems and fatalities recorded on British racecourses from flat racing and National Hunt racing during 1996, 1997 and 1998. Equine Vet J. 2001:33:478-86.

13. U.S. Department of Health and Human Services; Food and Drug Administration; Center for Biologics Evaluation and Research. Guidance for Industry: Preparation of IDEs and INDs for Products Intended to Repair or Replace Knee Cartilage [Internet]. 2011. Available from: https://www.fda.gov/ downloads/ucm288011.pdf.

14. European Medicines Agency; Committee For Advanced Therapies (CAT). Reflection paper on in-vitro cultured chondrocyte containing products for cartilage repair of the knee. [Internet]. 2010. Available from: http://www. ema.europa.eu/docs/en_GB/document_library/Scientific_guideline/2010/05/ WC500090887.pdf.

15. Smith RKW, Korda M, Blunn GW, Goodship AE. Isolation and implantation of autologous equine mesenchymal stem cells from bone marrow into the superficial digital flexor tendon as a potential novel treatment. Equine Vet J. 2003:35:99-102

16. Godwin EE, Young NJ, Dudhia J, Beamish IC, Smith RKW. Implantation of bone marrow-derived mesenchymal stem cells demonstrates improved outcome in horses with overstrain injury of the superficial digital flexor tendon. Equine Vet J. 2012:44:25-32.

17. Geburek F, Lietzau M, Beineke A, Rohn K, Stadler PM. Effect of a single injection of autologous conditioned serum (ACS) on tendon healing in equine naturally occurring tendinopathies. Stem Cell Res Ther. 2015;6:126.

18. Dominici M, Le Blanc K, Mueller I, Slaper-Cortenbach I, Marini F, Krause D, et al. Minimal criteria for defining multipotent mesenchymal stromal cells. The International Society for Cellular Therapy position statement. Cytotherapy. 2006;8:315-7.

19. Richardson LE, Dudhia J, Clegg PD, Smith R. Stem cells in veterinary medicine-attempts at regenerating equine tendon after injury. Trends Biotechnol. 2007;25:409-16.

20. Brehm W, Burk J, Delling U, Gittel C, Ribitsch I. Stem cell-based tissue engineering in veterinary orthopaedics. Cell Tissue Res. 2012;347:677-88.

21. Uder C, Brückner S, Winkler S, Tautenhahn HM, Christ B. Mammalian MSC from selected species: Features and applications. Cytometry A. 2018:93(1):32-49.

22. Burk J, Berner D, Brehm W. Hillmann A, Horstmeier C, Josten C, et al. Long-term cell tracking following local injection of mesenchymal stromal cells in the equine model of induced tendon disease. Cell Transplant. 2016;25:2199-211.

23. Smith RKW, Mcllwraith CW. Consensus on equine tendon disease: building on the 2007 Havemeyer symposium: consensus on equine tendon disease. Equine Vet J. 2012;44:2-6.

24. Burk J, Ribitsch I, Gittel C, Juelke H, Kasper C, Staszyk C, et al. Growth and differentiation characteristics of equine mesenchymal stromal cells derived from different sources. Vet J. 2013;195:98-106.

25. Paebst F, Piehler D, Brehm W, Heller S, Schroeck C, Tárnok A, et al. Comparative immunophenotyping of equine multipotent mesenchymal stromal cells: an approach toward a standardized definition. Cytom Part J Int Soc Anal Cytol. 2014;85:678-87.

26. Rantanen N, Jorgensen J, Genovese R. Ultrasonographic Evaluation of the Equine Limb: Technique. Ross MW, Dyson SJ Ed Diagn Manag Lameness Horse. 2nd ed. 2011. p. 182-205.

27. Vallance SA, Vidal MA, Whitcomb MB, Murphy BG, Spriet M, Galuppo LD Evaluation of a diode laser for use in induction of tendinopathy in the superficial digital flexor tendon of horses. Am J Vet Res. 2012;73:1435-44.

28. Crovace A, Lacitignola L, Rossi G, Francioso E. Histological and Immunohistochemical Evaluation of Autologous Cultured Bone Marrow Mesenchymal Stem Cells and Bone Marrow Mononucleated Cells in Collagenase-Induced Tendinitis of Equine Superficial Digital Flexor Tendon. Vet Med Int [Internet]. 2010 [cited 2015 Dec 2]; 2010. Available from: http:// www.ncbi.nlm.nih.gov/pmc/articles/PMC2859019/

29. Martinello T, Pascoli F, Caporale G, Perazzi A, lacopetti I, Patruno M. Might the Masson trichrome stain be considered a useful method for categorizing experimental tendon lesions? Histol Histopathol. 2015;30:963-9. 
30. Kittler J, Illingworth J. Minimum error thresholding. Pattern Recogn. 1986;19:41-7.

31. Hillmann A, Ahrberg AB, Brehm W, Heller S, Josten C, Paebst F, et al. Comparative characterization of human and equine mesenchymal stromal cells: a basis for translational studies in the equine model. Cell Transplant. 2016;25:109-24.

32. Pfaffl MW. Transcriptional biomarkers. Methods San Diego Calif. 2013;59:1-2.

33. Schnabel LV, Lynch ME, van der Meulen MCH, Yeager AE, Kornatowski MA Nixon AJ. Mesenchymal stem cells and insulin-like growth factor-I geneenhanced mesenchymal stem cells improve structural aspects of healing in equine flexor digitorum superficialis tendons. J Orthop Res Off Publ Orthop Res Soc. 2009;27:1392-8.

34. Bourin P, Bunnell BA, Casteilla L, Dominici M, Katz AJ, March KL, et al. Stromal cells from the adipose tissue-derived stromal vascular fraction and culture expanded adipose tissue-derived stromal/stem cells: a joint statement of the International Federation for Adipose Therapeutics and Science (IFATS) and the International Society for Cellular Therapy (ISCT). Cytotherapy. 2013;15:641-8.

35. Conze P, van Schie HT, van WR, Staszyk C, Conrad S, Skutella T, et al. Effect of autologous adipose tissue-derived mesenchymal stem cells on neovascularization of artificial equine tendon lesions. Regen Med. 2014:9:743-57.

36. Carvalho A de M, Badial PR, Álvarez LEC, Yamada ALM, Borges AS, Deffune E, et al. Equine tendonitis therapy using mesenchymal stem cells and platelet concentrates: a randomized controlled trial. Stem Cell Res Ther. 2013;4:85.

37. Burk J, Gittel C, Heller S, Pfeiffer B, Paebst F, Ahrberg AB, et al. Gene expression of tendon markers in mesenchymal stromal cells derived from different sources. BMC Res Notes. 2014;7:826.

38. Geburek F, Mundle K, Conrad S, Hellige M, Walliser U, van Schie HTM, et al. Tracking of autologous adipose tissue-derived mesenchymal stromal cells with in vivo magnetic resonance imaging and histology after intralesional treatment of artificial equine tendon lesions - a pilot study. Stem Cell Res Ther. 2016;7:21.

39. Yang $Y$, Zhang J, Qian Y, Dong S, Huang H, Boada FE, et al. Superparamagnetic Iron oxide is suitable to label tendon stem cells and track them in vivo with MR imaging. Ann Biomed Eng. 2013;41:2109-19.

40. Addicott B, Willman M, Rodriguez J, Padgett K, Han D, Berman D, et al. Mesenchymal stem cell labeling and in vitro MR characterization at $1.5 \mathrm{~T}$ of new SPIO contrast agent: Molday ION rhodamine-BTM. Contrast Media Mol Imaging. 2011;6:7-18.

41. Bourzac CA, Koenig JB, Link KA, Nykamp SG, Koch TG. Evaluation of ultrasmall superparamagnetic iron oxide contrast agent labeling of equine cord blood and bone marrow mesenchymal stromal cells. Am J Vet Res. 2014;75:1010-7

42. Wang L, Deng J, Wang J, Xiang B, Yang T, Gruwel M, et al. Superparamagnetic iron oxide does not affect the viability and function of adipose-derived stem cells, and superparamagnetic iron oxide-enhanced magnetic resonance imaging identifies viable cells. Magn Reson Imaging. 2009;27:108-19.

43. Delling $U$, Brehm W, Metzger $M$, Ludewig $E$, Winter $K$, Jülke $H$. In vivo tracking and fate of intra-Articularly injected superparamagnetic Iron oxide particle-labeled multipotent stromal cells in an ovine model of osteoarthritis. Cell Transplant. 2015;24:2379-90.

44. Astanina K, Simon Y, Cavelius C, Petry S, Kraegeloh A, Kiemer AK Superparamagnetic iron oxide nanoparticles impair endothelial integrity and inhibit nitric oxide production. Acta Biomater. 2014;10:4896-911.

45. Schäfer R, Ayturan M, Bantleon R, Kehlbach R, Siegel G, Pintaske J, et al. The use of clinically approved small particles of iron oxide (SPIO) for labeling of mesenchymal stem cells aggravates clinical symptoms in experimental autoimmune encephalomyelitis and influences their in vivo distribution. Cell Transplant. 2008;17:923-41.

46. Williams IF, McCullagh KG, Goodship AE, Silver IA. Studies on the pathogenesis of equine tendonitis following collagenase injury. Res Vet Sci. 1984;36:326-38.

47. Little D, Schramme M. Ultrasonographic and MRI evaluation of a novel tendonitis model in the horse. Vet Surg. 2006;35:E15.

48. Nixon AJ, Dahlgren LA, Haupt JL, Yeager AE, Ward DL. Effect of adiposederived nucleated cell fractions on tendon repair in horses with collagenase-induced tendinitis. Am J Vet Res. 2008;69:928-37.

49. De Becker A, Riet IV. Homing and migration of mesenchymal stromal cells: how to improve the efficacy of cell therapy? World J Stem Cells. 2016;8:73-87.
50. Chapel A, Bertho JM, Bensidhoum M, Fouillard L, Young RG, Frick J, et al. Mesenchymal stem cells home to injured tissues when co-infused with hematopoietic cells to treat a radiation-induced multi-organ failure syndrome. J Gene Med. 2003;5:1028-38.

51. Carvalho AM, Yamada ALM, Golim MA, Álvarez LEC, Hussni CA, Alves ALG. Evaluation of mesenchymal stem cell migration after equine tendonitis therapy. Equine Vet J. 2014;46:635-8.

52. Guest DJ, Smith MRW, Allen WR. Equine embryonic stem-like cells and mesenchymal stromal cells have different survival rates and migration patterns following their injection into damaged superficial digital flexor tendon. Equine Vet J. 2010:42:636-42.

53. Dakin SG, Dudhia J, Smith RKW. Resolving an inflammatory concept: the importance of inflammation and resolution in tendinopathy. Vet Immunol Immunopathol. 2014;158:121-7.

\section{Ready to submit your research? Choose BMC and benefit from:}

- fast, convenient online submission

- thorough peer review by experienced researchers in your field

- rapid publication on acceptance

- support for research data, including large and complex data types

- gold Open Access which fosters wider collaboration and increased citations

- maximum visibility for your research: over $100 \mathrm{M}$ website views per year

At BMC, research is always in progress.

Learn more biomedcentral.com/submissions 